
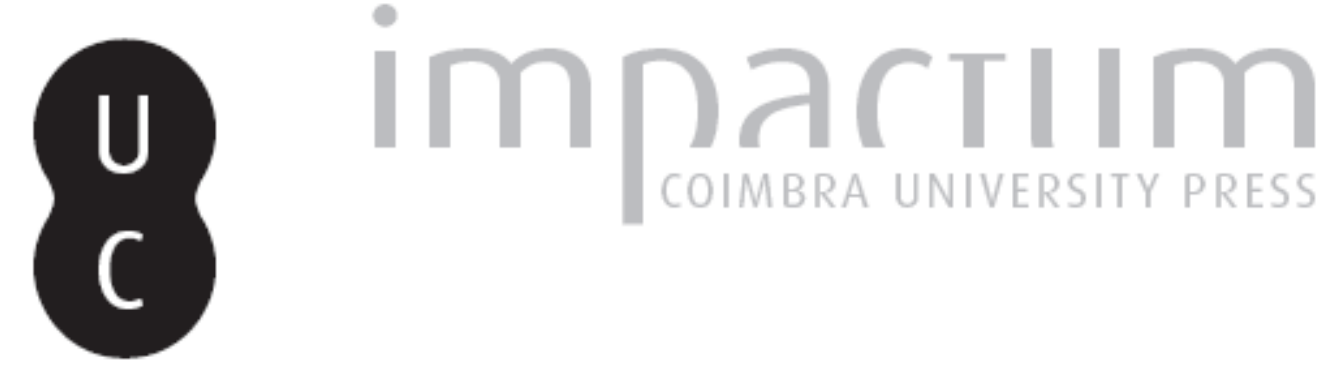

\title{
Mapeamento dos compartimentos do relevo do município de Estrela do Norte-SP e adjacências: a partir de técnicas de visualização estereoscópica digital
}

Autor(es): $\quad$ Felipe, Mayara Cristina de Paula; Nunes, João Osvaldo Rodrigues

Publicado por: Imprensa da Universidade de Coimbra

URL

persistente:

URI:http://hdl.handle.net/10316.2/40778

DOI:

DOI:https://doi.org/10.14195/0871-1623_35_9

Accessed : $\quad$ 26-Apr-2023 12:21:25

A navegação consulta e descarregamento dos títulos inseridos nas Bibliotecas Digitais UC Digitalis, UC Pombalina e UC Impactum, pressupõem a aceitação plena e sem reservas dos Termos e Condições de Uso destas Bibliotecas Digitais, disponíveis em https://digitalis.uc.pt/pt-pt/termos.

Conforme exposto nos referidos Termos e Condições de Uso, o descarregamento de títulos de acesso restrito requer uma licença válida de autorização devendo o utilizador aceder ao(s) documento(s) a partir de um endereço de IP da instituição detentora da supramencionada licença.

Ao utilizador é apenas permitido o descarregamento para uso pessoal, pelo que o emprego do(s) título(s) descarregado(s) para outro fim, designadamente comercial, carece de autorização do respetivo autor ou editor da obra.

Na medida em que todas as obras da UC Digitalis se encontram protegidas pelo Código do Direito de Autor e Direitos Conexos e demais legislação aplicável, toda a cópia, parcial ou total, deste documento, nos casos em que é legalmente admitida, deverá conter ou fazer-se acompanhar por este aviso.

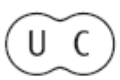




\section{Cadernos de}
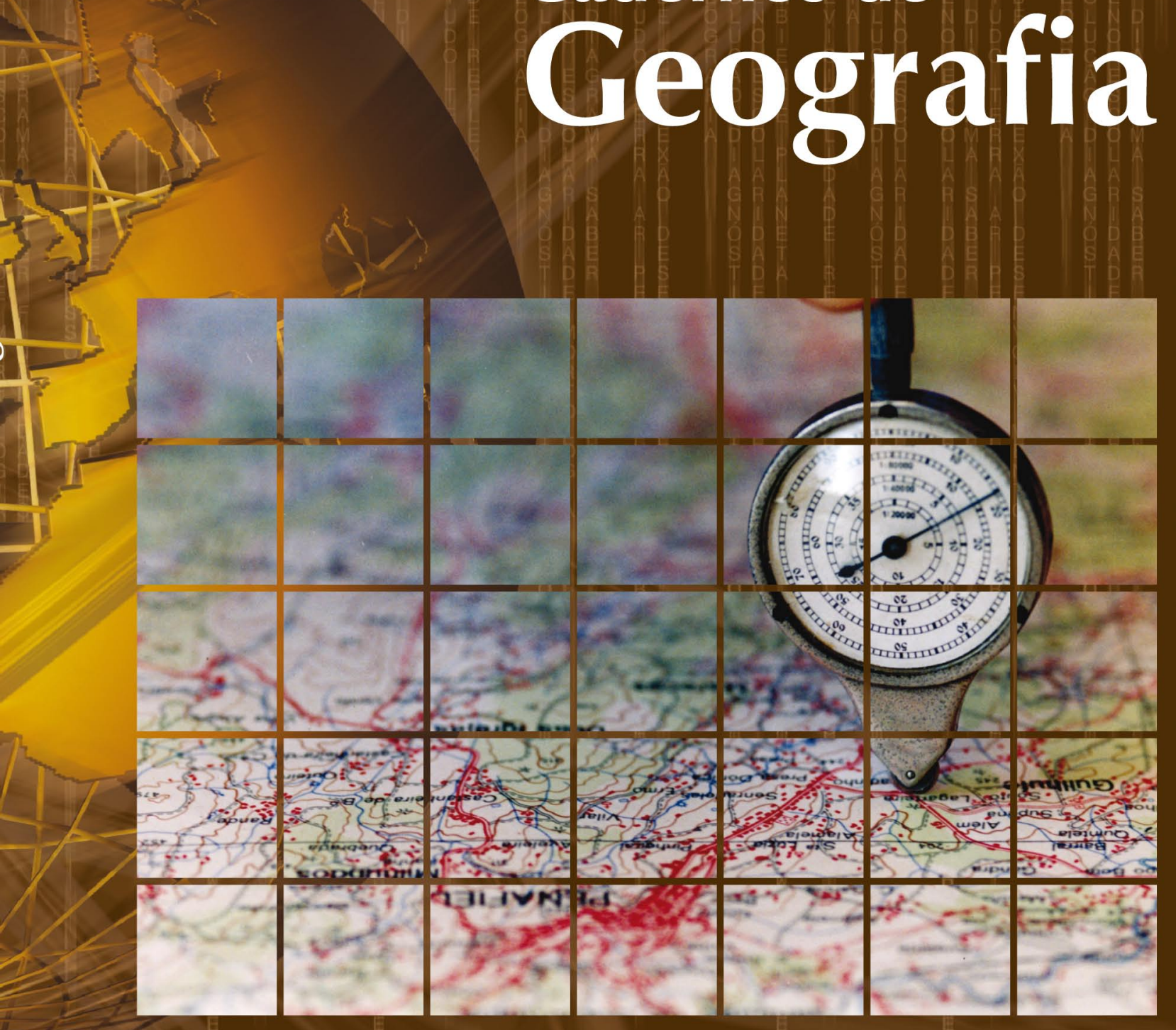

Imprensa da Universidade de Coimbra

Faculdade de Letras | Universidade de Coimbra 


\title{
Mapeamento dos compartimentos do relevo do município de Estrela do Norte-SP e adjacências - a partir de técnicas de visualização estereoscópica digital Mapping of relief compartments of the municipality of Estrela do Norte-SP and adjacencies - from digital stereoscopic visualization techniques
}

\author{
Mayara Cristina de Paula Felipe \\ Laboratório de Sedimentologia e Análise de Solos da Faculdade de Ciências e Tecnologia - Universidade Estadual Paulista \\ may-cris@hotmail.com
}

\section{João Osvaldo Rodrigues Nunes}

Professor Livre Docente do Departamento de Geografia da Faculdade de Ciências e Tecnologia -Universidade Estadual Paulista joaosvaldo@fct.unesp.br

\section{Resumo:}

O mapa geomorfológico é considerado um importante instrumento na pesquisa da paisagem, pois auxilia na análise dos processos relacionados ao relevo. Desse modo, o presente trabalho teve como objetivo, elaborar o mapeamento dos compartimentos de relevo do município de Estrela do Norte-SP e adjacências, localizado no Extremo Oeste do Estado de São Paulo, utilizando técnicas de estereoscopia digital com restituição - 3D, através das imagens ALOS/PRISM, vinculados a trabalhos de campo identificando os solos, as formações geológicas e as dinâmicas atuais do uso e ocupação dos solos.

Palavras-chave: Mapeamento. Relevo. Estereoscopia digital. Estrela do Norte-SP.

\section{Abstract:}

The geomorphological map is currently considered an important tool in the landscape of research, because it helps in the analysis of processes related to relief. Thus, this work was aimed to elaborate the mapping of the relief compartments of the Estrela do Norte-SP, using digital stereoscopy techniques with 3D restitution over ALOS/PRISM images, related to field surveys in order to identify soil types, geologic formations and the current dynamics of the use and occupation of land.

Keywords: Mapping. Relief. Digital stereoscopy. Estrela do Norte-SP.

\section{Introdução}

A geomorfologia tem contribuído para compreender a inter-relação entre os processos naturais e sociais que atuam sobre o relevo. Entre as diferentes formas de se trabalhar na geomorfologia, a cartografia geomorfológica é uma que se destaca, pois possibilita, conforme a escala, entender a dinâmica de formação das morfologias mapeadas, identificar os diferentes compartimentos do relevo (vertentes, topos e fundo de vales), auxiliando na compreensão da evolução da ocupação do relevo pela sociedade e em estudos diagnósticos e prognósticos nas áreas urbanas e rurais.

Desse modo, destacam-se os estudos referentes à análise dos processos morfodinâmicos (tempo histórico) em relação aos processos morfogenéticos (tempo geológico). Na morfogênese, busca-se compreender as origens das formas, ou seja, "tempo que escoa”. Já a morfodinâmica, refere-se ao tempo histórico ou "tempo que faz", o qual introduz a dimensão antropogênica na natureza (Suertegaray e Nunes, 2001).
A região do Extremo Oeste do Estado de São Paulo carece de trabalhos de mapeamento geomorfológico na escala do planejamento urbano e regional. Os documentos que envolvem a maioria dos municípios da área em questão, devido a sua escala, estão voltados para um planejamento mais amplo, são exemplos, os mapas geomorfológicos do IPT (1981b) na escala 1:1.000.000 e o de Ross e Moroz (1997) na escala de 1:500.000.

A falta de documentos nessa escala faz com que haja uma lacuna em nível de planejamento municipal. Muitas vezes os agentes sociais públicos e privados não respeitam as características do meio físico, resultando em ocupações inadequadas das formas de relevos como as planícies aluviais, áreas de nascentes, etc. Além disso, gera uma lacuna na elaboração de estudos acadêmicos, onde a morfologia do relevo apresenta-se como importante aspecto a ser considerado na compreensão dos fatores responsáveis pela história de ocupação e expansão sobre as diversas formas de relevo.

A região do Extremo Oeste do Estado de São Paulo é caracterizada pelo intenso processo de 
desmatamento, o qual se iniciou principalmente no século $X X$ em virtude do deslocamento de mineiros e desbravadores para essa porção do território paulista. Por conseguinte, a ocupação dessas novas áreas foi marcada pela devastação sem precedentes do meio ambiente, assim, à medida que ocorria o desmatamento das áreas de florestas primitivas, os solos eram ocupados principalmente pela cultura do café, que ao longo da história foi sendo substituída pelos cultivos de algodão, de amendoim, de menta, e atualmente pela cana de açúcar e pastagem. Essas ações articuladas com as características do meio físico formaram um dos piores quadros de degradação erosiva do Estado de São Paulo, constituídos por processos de ravinamento e voçorocamento.

Nesse contexto, o objetivo principal do presente trabalho foi elaborar o Mapa dos Compartimentos do Relevo do município de Estrela do Norte-SP e adjacências (Figura 1), os quais vêm sofrendo ao longo dos anos sérios problemas de degradação ambiental, em virtude da interferência da sociedade na natureza sem práticas conservacionistas. Para tal atividade, utilizaram-se técnicas de visualização estereoscópica digital a partir das imagens do satélite japonês Advanced Land Observing Satellite (ALOS), sensor Panchromatic Remote-sensing Instrument for Stereo Mapping (PRISM) - ALPSMN063234050 e ALPSMN063234055, com resolução Ground Sample Distance (GSD) de 2,5 metros.

Vale ressaltar, que o Mapa de Compartimentos do Relevo é parte de um projeto mais amplo, coordenado pelo Professor Livre Docente João Osvaldo Rodrigues Nunes, em que o objetivo é mapear os principais aspectos geomorfológicos do Extremo do Estado de São Paulo em escala de detalhe ou semidetalhada por intermédio da estereoscopia analógica ou no ambiente digital.

Como documentos cartográficos resultantes, pode-se mencionar os mapas geomorfológicos das áreas urbanas (NUNES et al., 2006) e rurais de Presidente Prudente-SP (Nunes e Fushimi, 2010), das cidades de Marília-SP (Santos, 2006) e de Álvares Machado-SP (Vinha, 2011), os mapas de compartimentos do relevo de parte dos municípios de Santo Anastácio-SP (Nunes et al., 2014) e de Estrela do Norte-SP (Felipe, 2015).

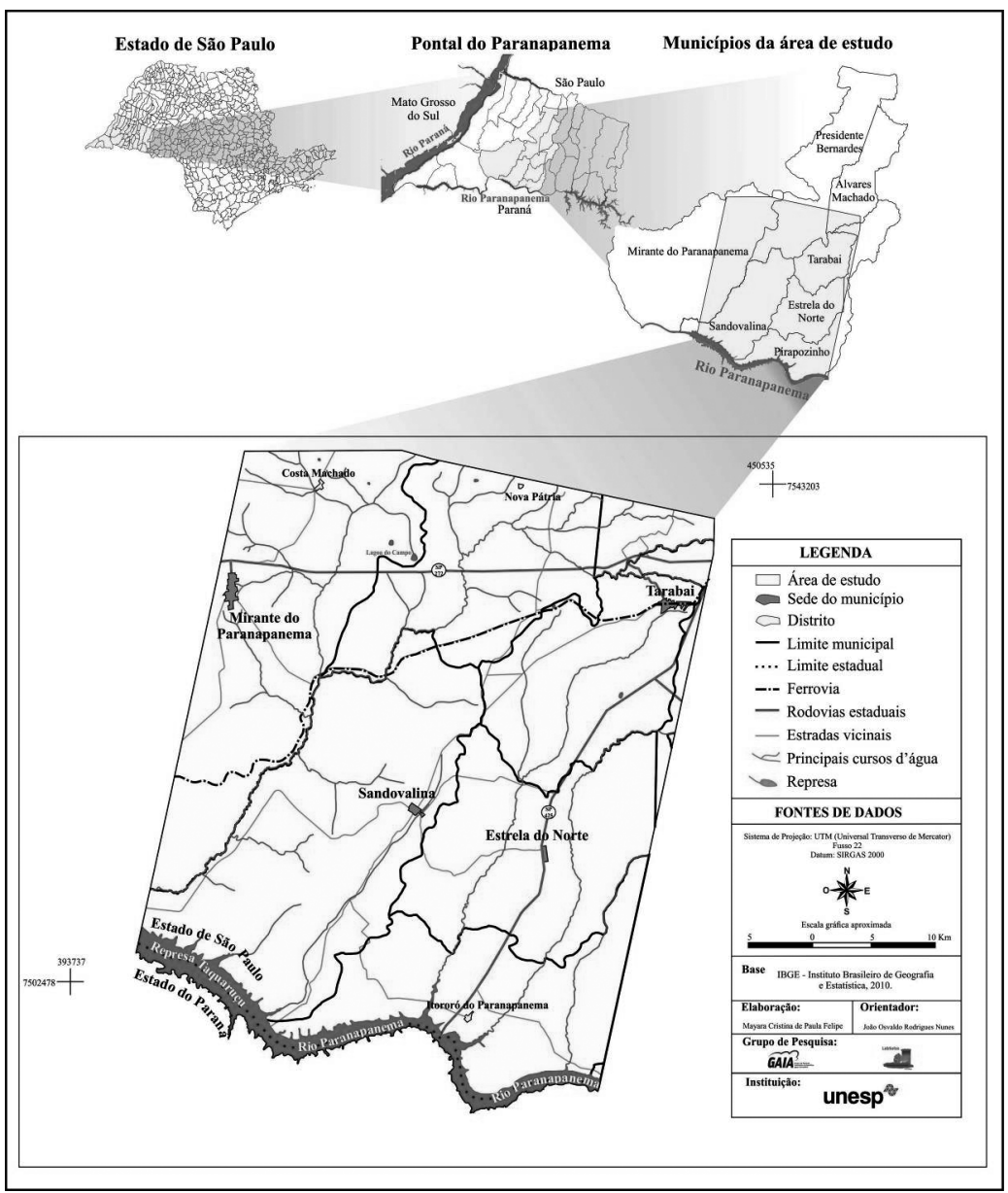

Figura 1

Localização da área de estudo.

Fonte: Felipe (2015). 


\section{Caracterização da área de estudo}

O município de Estrela do Norte está localizado no Extremo Oeste do Estado de São Paulo. Sua área territorial é de $263,420 \mathrm{~km}^{2}$ e sua população é de 2.658 habitantes, sendo 559 rural e 2.099 urbana (IBGE, 2010).

Geomorfologicamente a área de estudo está localizada na Bacia Sedimentar do Paraná (morfoestrutura) e no Planalto Ocidental Paulista (morfoescultura), mais precisamente no Planalto Centro Ocidental. Nesta unidade predominam as formas de relevo denudacionais, cujas formas dominantes são as colinas amplas e baixas de topos convexos e topos tabulares planos, com altimetria em torno de 300 a 600 metros, declividade variando entre 10 a $20 \%$ e com o predomínio de Latossolos e de Argissolos (Ross e Moroz, 1997). Moroz- Caccia Gouveia et al. (2014), realizaram um estudo na Unidade de Gestão de Recursos Hídricos (UGRH) Paranapanema no qual elaboraram o Mapa de Fragilidade Geoambiental desta unidade de gerenciamento. A fragilidade foi obtida a partir da análise integrada do relevo, solos, litologia, cobertura vegetal/uso das terras e pluviosidade. Em relação ao estado de São Paulo, utilizou-se como base o Mapa Geomorfológico elaborado por Ross e Moroz (1997). Dessa forma, na área de estudo identificaram o Planalto do Médio Paranapanema (2.3.7), Planalto Centro Ocidental de Topos Tabulares (2.3.10) e o Planalto Centro Ocidental de Topos Convexos (2.3.11) .

O Planalto do Médio Paranapanema (2.3.7) possui colinas com topos aplainados, altimetria entre 350 a 600 metros, declividade maior que $6 \%$, baixa dissecação do relevo, com a predominância de Latossolos e Nitossolos e baixa fragilidade face aos processos erosivos.

O Planalto Centro Ocidental de Topos Tabulares (2.3.10), cuja forma de relevo dominante são as colinas com topos aplainados, com altimetria entre 400 a 500 metros, com predominância de Argissolos e Latossolos, possui fragilidade média a processos erosivos nos setores aplainados dos topos, entretanto, face às características texturais dos solos, os setores de vertentes mais inclinados são bastante suscetíveis à erosão linear.

No Planalto Centro Ocidental de Topos Convexos (2.3.11) a forma de relevo dominante são as colinas amplas com topos convexos, com altimetria entre 350 e 550 metros, com a predominância de Argissolos, possuindo fragilidade média a processos erosivos nos setores aplainados dos topos, entretanto, face às características texturais dos solos, os setores de vertentes mais inclinados são extremamente suscetíveis à erosão linear.

A Bacia Sedimentar do Paraná abrange uma área de cerca de $1.600 .000 \mathrm{~km}^{2}$, foi formada a partir do Devoniano Inferior, sendo constituída principalmente por rochas sedimentares e ígneas da idade Mesozóica e por depósitos recentes da idade Cenozóica (IPT, 1981a).

Conforme a coluna litoestratigráfica da Bacia do Paraná, as formações geológicas dominantes que afloram na região do Extremo Oeste Paulista, pertencem ao Grupo São Bento - Formação Serra Geral-JKsg (4,3\%); ao Grupo Bauru - Formações Caiuá-Kc (28,7\%), Santo Anástácio-Ksa (2,7\%), Adamantina-Ka (62,2\%), e os Depósitos Cenozóicos-Qa (2,1\%) (IPT, 1981a).

De tal modo, o Extremo Oeste Paulista é formado principalmente pelas rochas do Grupo Bauru e Grupo São Bento. As rochas do Grupo Bauru guardam um grande registro geológico do Cretáceo Superior, sendo constituídas predominantemente por formações areníticas, em algumas regiões cimentadas por carbonato de cálcio. Ao longo dos vales dos principais rios o basalto se expõe, Grupo São Bento, em ocorrência descontínuas, exceto ao longo do Rio Paranapanema e do Rio Pardo onde afloram extensivamente (IPT, 1981a).

$\mathrm{Na}$ área de estudo, estão presentes as Formações Santo Anastácio, Adamantina e Formação Caiuá pertencentes ao Grupo Bauru e Formação Serra Geral pertencente ao Grupo São Bento.

\section{Procedimentos Metodológicos}

A caracterização geomorfológica, foi elaborada de acordo com os dois primeiros níveis de abordagem proposto por Ab'Saber (1969): Compartimentação Topográfica e Estrutura Superficial da Paisagem.

O primeiro nível compreende: “[...] o entendimento da compartimentação da topografia regional, assim como, da caracterização e descrição, tão exatas quanto possíveis, das formas de relevo de cada um dos compartimentos estudados" (Ab'Saber, 1969: 1-2).

No segundo nível, Estrutura Superficial da Paisagem, é possível obter o conhecimento da evolução histórica do relevo, por meio dos depósitos correlativos, como afirma Ab'Saber (1969: 2): “[...] procura-se obter informações sistemáticas sobre a estrutura superficial das paisagens referentes a todos os compartimentos e formas de relevos observados. Através deste estudo e da estrutura superficial, até certo ponto estáticos, obtêm-se idéia da cronogeomorfologia e as primeiras proposições interpretativas sobre a seqüência dos processos paleo-climáticos e morfoclimáticos da área em estudo".

Em relação aos procedimentos utilizados na elaboração do mapeamento dos compartimentos de relevo, as principais referências foram: Cailleux e Tricart (1956), e Tricart (1965), compreendendo a $6^{\text {a }}$ unidade taxonômica com unidade de superfície de $10^{-2}$ e Ross (1992) que corresponde ao $4^{\circ}, 5^{\circ}$ e $6^{\circ}$ táxon. Em ambos, foram realizadas adaptações para a área de estudo.

Na primeira etapa de elaboração do Mapa dos Compartimentos do Relevo do município de Estrela do Norte e adjacências, realizou-se um trabalho de campo para obter o rastreamento dos pontos de controle com receptor GPS (Global Positioning System) de precisão, com o objetivo de georreferenciar as 
imagens do satélite ALOS/PRISM. Dessa forma, foram determinados 16 pontos de controle (Figura 2).

As imagens ALOS/PRISM são disponibilizadas pelo satélite japonês ALOS, o qual colocou a disposição da comunidade as imagens do sensor PRISM, as quais são pancromáticas e com resolução espacial de $2,5 \mathrm{~m}$. Este sensor é composto por três sistemas ópticos independentes, um com visada nadir e dois com visadas inclinadas para frente e para trás, o que permite que suas imagens tenham visão estereoscó-

pica (Barros et al., 2008).
Em virtude da alta precisão necessária para o georreferenciamento das imagens ALOS/PRISM, utilizou-se o receptor Geodésico Hiper de dupla frequência (L1 e L2). Vale ressaltar, que a escolha dos pontos de controle levou em consideração alvos que facilitaria o georreferenciamento. Assim, estavam situados, sobretudo, em áreas com pouca arborização e em cruzamentos de estradas.

Posteriormente, no Sistema de Processamento de Imagens PushAnaglifo, programa desenvolvido pelo Prof. Dr. Júlio Kiyoshi Hasegawa, utilizou-se a técnica

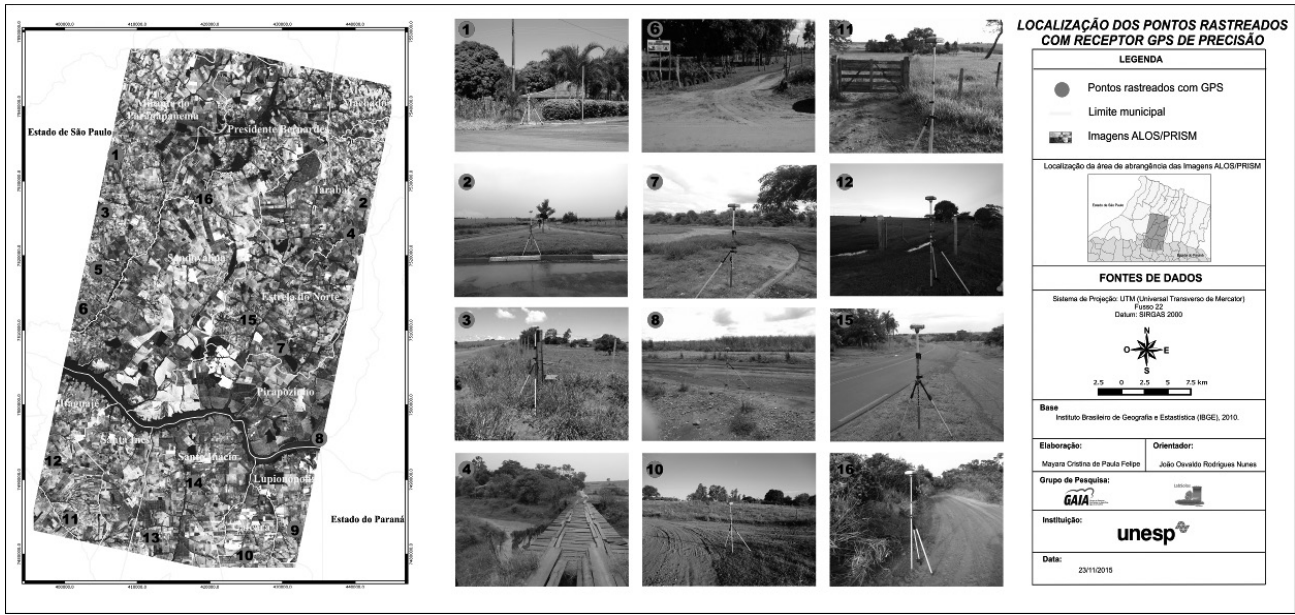

Figura 2

Localizacão dos 16 pontos de controle na imagem ALOS/PRISM. Fonte: Felipe (2015)

de Restituição - 3D (3 Dimensões), obtendo a visualização estereoscópica a partir do método anaglifo. Dessa forma, com óculos de lentes vermelha e azul na frente do computador (Figura 3), foi colocando-se as marcas flutuantes (medição) sobre o ponto no estereomodelo e transmitindo para o arquivo de desenho.

A estereoscopia com o método anaglifo utiliza o conceito de filtragem dos canais que compõem a imagem, assim uma das imagens correspondente a um dos olhos, é visualizada na banda do vermelho, já a outra imagem do par estéreo é visualizada na banda do verde. Desse modo, as duas imagens com os canais de cores diferentes são projetadas na tela do computador e as lentes (vermelha e azul) dos óculos do observador filtra a cor e obstrui a imagem indesejada não correspondente.

De acordo com Amorim (2000: 12): "Se o observador utiliza óculos cuja lente da direita for vermelha

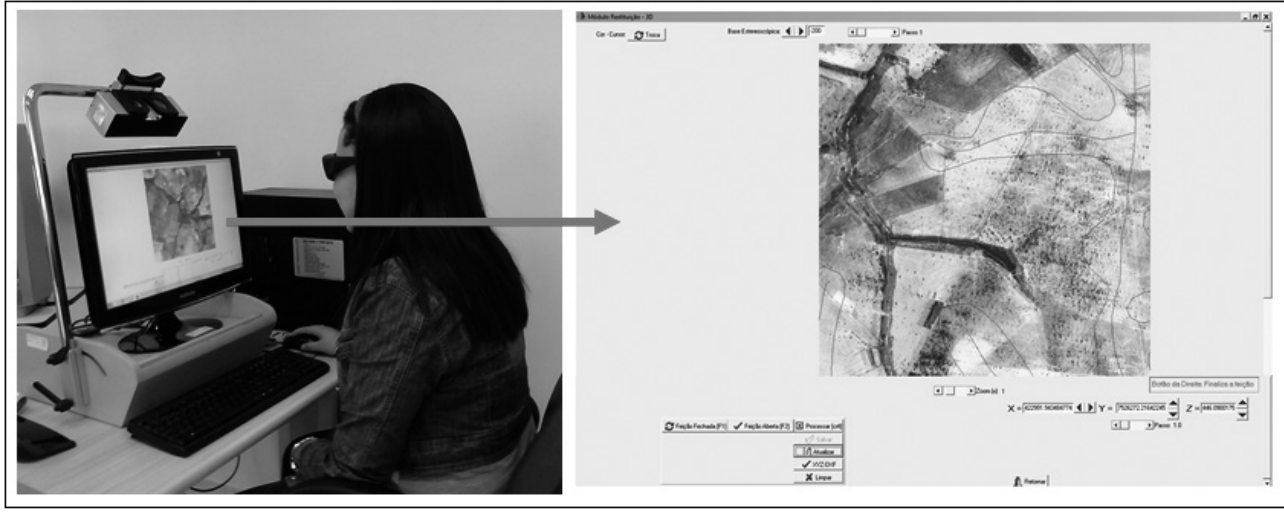

Figura 3

Extração das feições geomorfológicas a partir do método anaglifo.

Fonte: Felipe (2015) 
e a da esquerda for ciano, o olho esquerdo vê apenas a imagem da esquerda e o olho da direita, apenas a imagem da direita, formando assim a imagem tridimensional em tons de cinza".

A extração dos compartimentos geomorfológicos e respectivas feições morfológicas seguiram uma sequência: primeiramente foram extraídos os cursos de água, em seguida, delimitados as planícies aluviais e alvéolos, os topos das colinas, os divisores de água, as cabeceiras de drenagem em formato de anfiteatro e, por fim, a caracterização dos fundos de vale chatos (em berço) e encaixados (em "V") e dos colos topográficos (Figura 4).

Ao término da extração das feições geomorfológicas e dos compartimentos de relevo, realizou- se a reprodução das formas em ambiente SIG (Sistema de Informação Geográfica), o software utilizado foi o QGIS 2.4.0., os arquivos resultantes foram transformados em shapefiles: cursos de água (linha), planícies aluviais (polígono), topos das colinas (polígono) e divisores de água (linha).

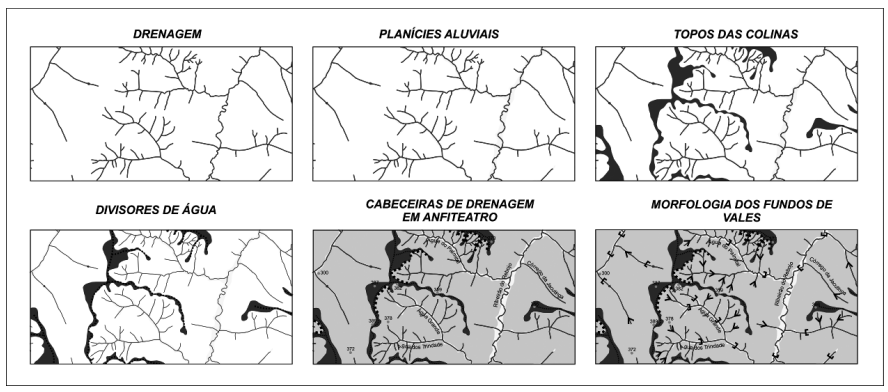

\section{Figura 4}

Vetorização das feições geomorfológicas. Fonte: Felipe (2015).

A legenda foi elaborada de acordo com o Mapa Geomorfológico do perímetro urbano de Presidente Prudente - SP, desenvolvido por Nunes et al. (2006).

Vale ressaltar, que foram realizados trabalhos de campo de forma sistemática no decorrer da pesquisa, onde foi possível atualizar e verificar os dados mapeados, bem como coletar materiais e informações que não estão disponíveis nas bases cartográficas.

\section{Resultados e discussões}

A elaboração do Mapa dos Compartimentos do Relevo do município de Estrela do Norte-SP e adjacências (Figura 5) associado aos trabalhos de campo possibilitaram a identificação de três principais compartimentos:

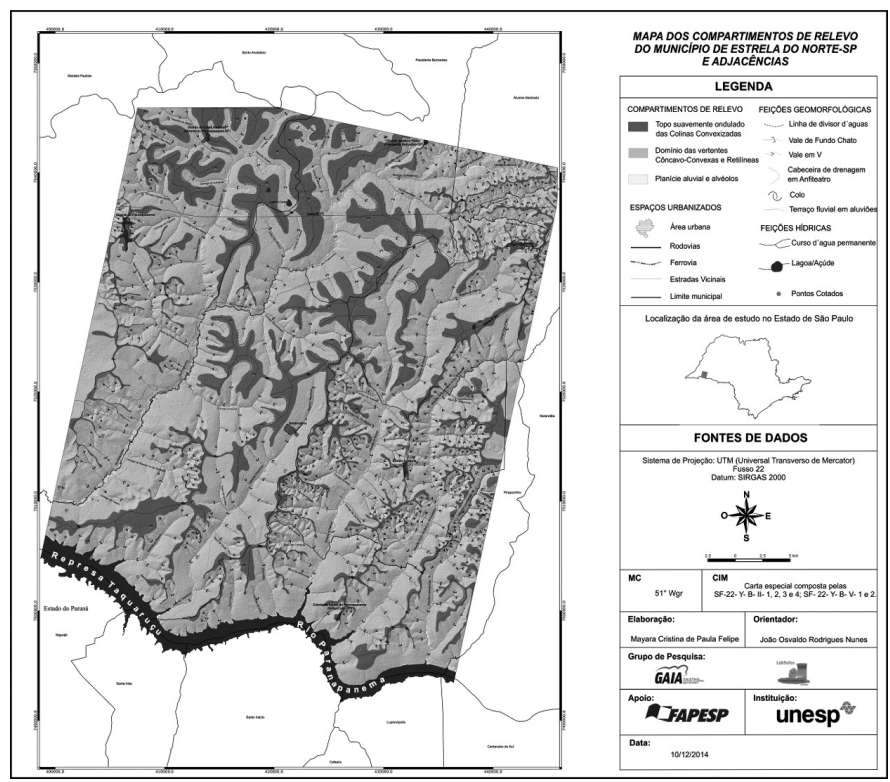

Figura 5

Mapa dos compartimentos de relevo do município de Estrela do Norte-SP e adjacências.

Fonte: Felipe (2015). 
- Topos suavemente ondulados das colinas convexizadas com a presença de solos desenvolvidos (associação Latossolos Vermelhos);

- Domínio das vertentes côncavas, convexas e retilíneas com a ocorrência de solos rasos a desenvolvidos, sendo que os solos rasos estão associados aos Neossolos Regolíticos e os solos desenvolvidos estão associados aos Argissolos Vermelhos.

- Planícies aluviais e alveolares com o predomínio dos solos hidromórficos, principalmente os Planossolos e os Gleissolos, sendo frequente também a presença de materiais sedimentares e manufaturados de origem tecnogênica.
Observaram-se dois padrões de compartimentos de relevos em relação aos tipos de colinas. 0 primeiro apresenta topos amplos e suavemente ondulados, com declividades entre 5 a 10\%, morfologia de vertentes retilíneas, com densidades de drenagem esparsa, plano paralelo com amplos interflúvios vinculados a estrutura geológica (baixos e altos estruturais), e presença de planícies aluviais com morfologias em fundo chato (em berço).

Em relação ao segundo padrão, este apresenta relevos de colinas baixas, topos estreitos alongados e alguns aguçados, com predomínio de declividades acima de $20 \%$ e vertentes mais convexas. Isto se
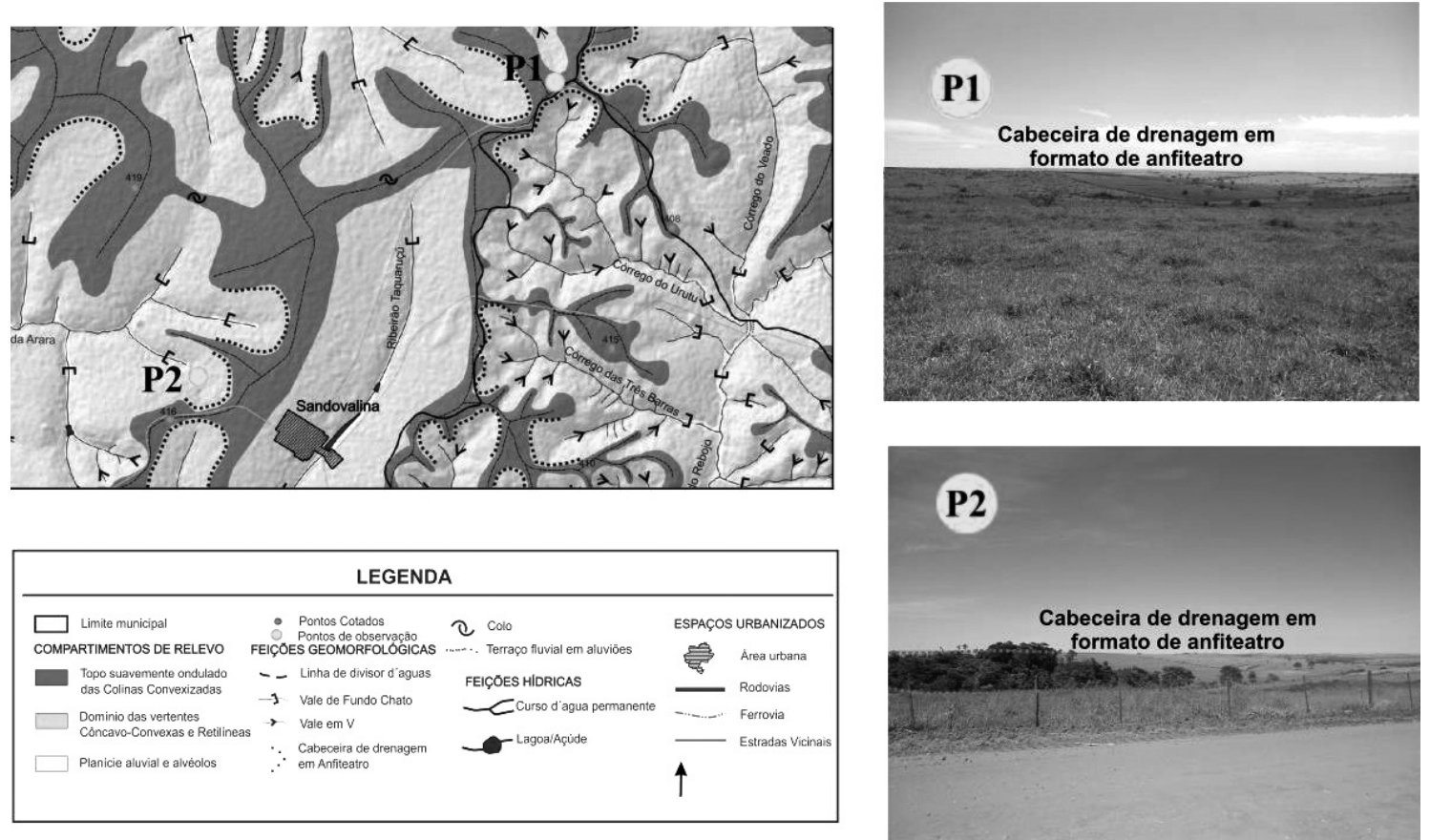

Figura 6

Pontos de observação com cabeceira de drenagem

em formato de anfiteatro.

Fonte: Felipe (2015).

reflete nas densidades de drenagem médias, com padrões dendríticos, dimensões interfluviais menores e morfologias de fundos vales encaixados em V.

Nos setores com colinas amplas de topos suavemente ondulados com amplos interflúvios, foram analisados 23 pontos de observação.

As cabeceiras de drenagem em formato de anfiteatro, de modo geral, seguem um padrão de localização nas vertentes côncavas (Figura 6), essas áreas apresentam-se bastante alteradas em virtude da retirada da cobertura vegetal, ocasionando o desaparecimento de algumas nascentes.

Nas porções mais planas do relevo, vem ocorrendo à plantação da cana de açúcar e na última década a plantação de soja. Na região do Pontal do Paranapanema o setor canavieiro tem expandido seus canaviais, por conseguinte, vem ocorrendo a implantação de novas agroindústrias por toda a região.
Dessa forma, os pontos de observação 3 , 4 e 5 (Figura 7) correspondem, em sua maioria, às áreas com topos amplos, de colinas suavemente onduladas e com o predomínio do cultivo da cana de açúcar. Vale ressaltar, que nesses espaços têm-se principalmente a ocorrência dos Latossolos Vermelhos, colinas de topos amplos e aplainados com vertentes retilíneas e extensos comprimentos de rampa e baixa declividades $(0-10 \%)$, características que propiciam o plantio de culturas.

No ponto de observação 5 , verificou-se a queima da palha da cana, embora esta prática esteja sendo extinta de maneira gradativa há ainda muitos que desrespeitam a lei, gerando desse modo, graves danos à sociedade, principalmente no que diz respeito ao meio ambiente e a saúde pública. Nesse sentido, Roseiro e Takayanagui, (2004) apud Barreto e Thomaz Jr (2012: 59) afirmam que:“[...] este 
processo acaba interferindo diretamente na saúde da população, pois a combustão da palha da cana- de-açúcar libera poluente e o principal dano é o prejuízo à qualidade do ar, e, consequentemente, da saúde, pela excessiva emissão de monóxido de carbono e ozônio, trazendo também danos ao solo, às plantas naturais e cultivadas, a fauna e a população".

De acordo com Barreto e Thomaz Jr. (2012), o Pontal do Paranapanema tem se tornado o novo alvo para a expansão do agronegócio canavieiro, em virtude da: "[...] disponibilidade de terras, a baixa concentração de unidades (se comparar com outras regiões do estado de $\mathrm{SP}$ ), somados a acessibilidade (eixos rodoviários), torna a região atrativa e favorável para o cultivo dessa monocultura e isso tem atraído muitos investidores de todo o Brasil para a região". (Barreto e Thomaz Jr, 2012: 52).

Portanto, a instalação das unidades canavieiras tem ocasionado uma série de problemas nos municípios, como o assoreamento dos cursos de água em virtude da destruição das matas ciliares e nascentes dos rios, não respeitando as áreas de preservação permanente. Sem falar no uso intensivo e abusivo dos agrotóxicos por meio da pulverização aérea, preju-
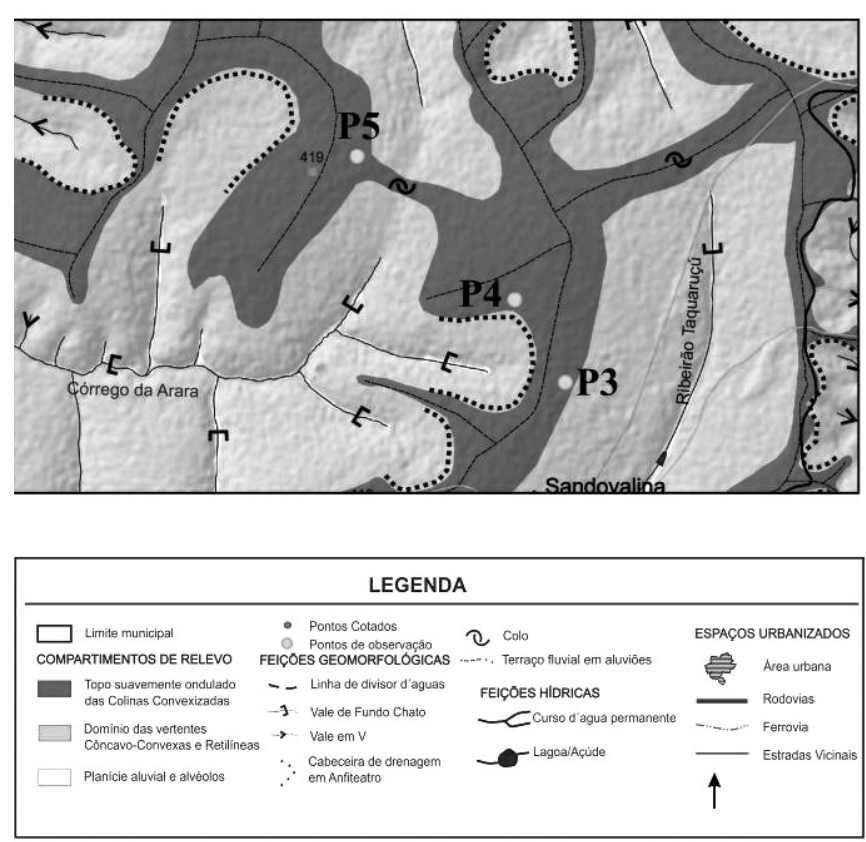
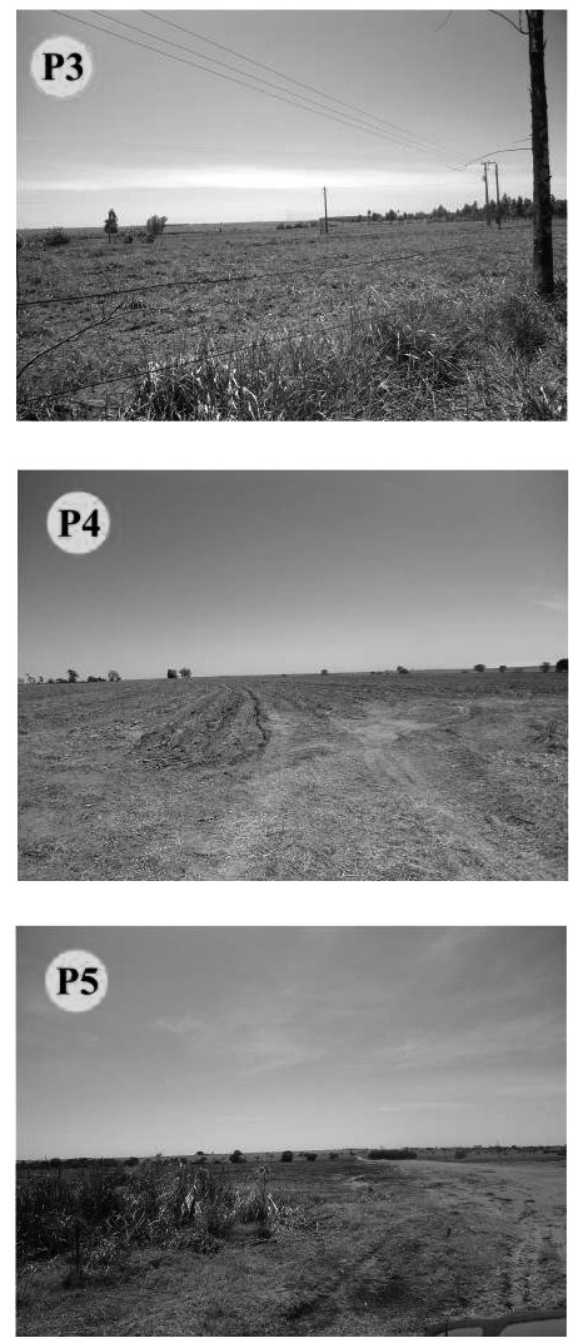
dicando diretamente a agricultura familiar e ocasionado a contaminação dos cursos de água e do solo.

No setor de topos estreitos alongados e alguns aguçados, foram analisados 9 pontos de observação, como exemplo, temos o ponto de observação 6 que se refere a uma colina com topo estreito e cobertura vegetal de gramíneas. Nos topos das colinas verificou-se a presença de Latossolos (Figura 8).

De modo geral na área mapeada identificaram-se 3 compartimentos geomorfológicos, constituídos por dois padrões de morfologias de topos das colinas diferenciados, bem como também o domínio das vertentes e as planícies aluviais e alveolares.

0 primeiro padrão compreende o setor central, onde as colinas apresentam topos amplos e suavemente ondulados, com predomínio de declividades entre 5 a 10\%, morfologia de vertentes retilíneas, densidade de drenagem esparsa, padrões de drenagem plano paralelo com amplos interflúvios vinculada a estrutura geológica, e presença de planícies aluviais com morfologias em fundo chato (em berço). Predominam os Latossolos Vermelhos profundos, sendo frequente nessa paisagem o cultivo da cana de açúcar e soja. O segundo padrão de colinas está localizado nas bordas do setor central, compreendendo relevos de colinas baixas, topos estreitos alongados e alguns aguçados, com predomínio de declividades acima de $20 \%$ e vertentes mais convexizadas. Isto se reflete nas densidades de drenagem médias, com padrões dendríticos, dimensões interfluviais menores e morfologias de fundos de vales encaixados em "V". Predominam os Argissolos Vermelho-Amarelos e Neossolos Litólicos. Identificou-se que nas áreas dos topos das colinas amplas ocorre o predomínio de Latossolos Vermelhos, com poucas atividades erosivas. Nas vertentes, onde predominam Argissolos Vermelho-Amarelos e Neossolos Litólicos, observaram-se vários processos erosivos do tipo sulcos, ravinas e voçorocas. E nas planícies aluviais, com a presença de Planossolos, Gleissolos e Depósitos tecnogênicos, observaram-se sérios problemas de assoreamento e retirada das matas ciliares.

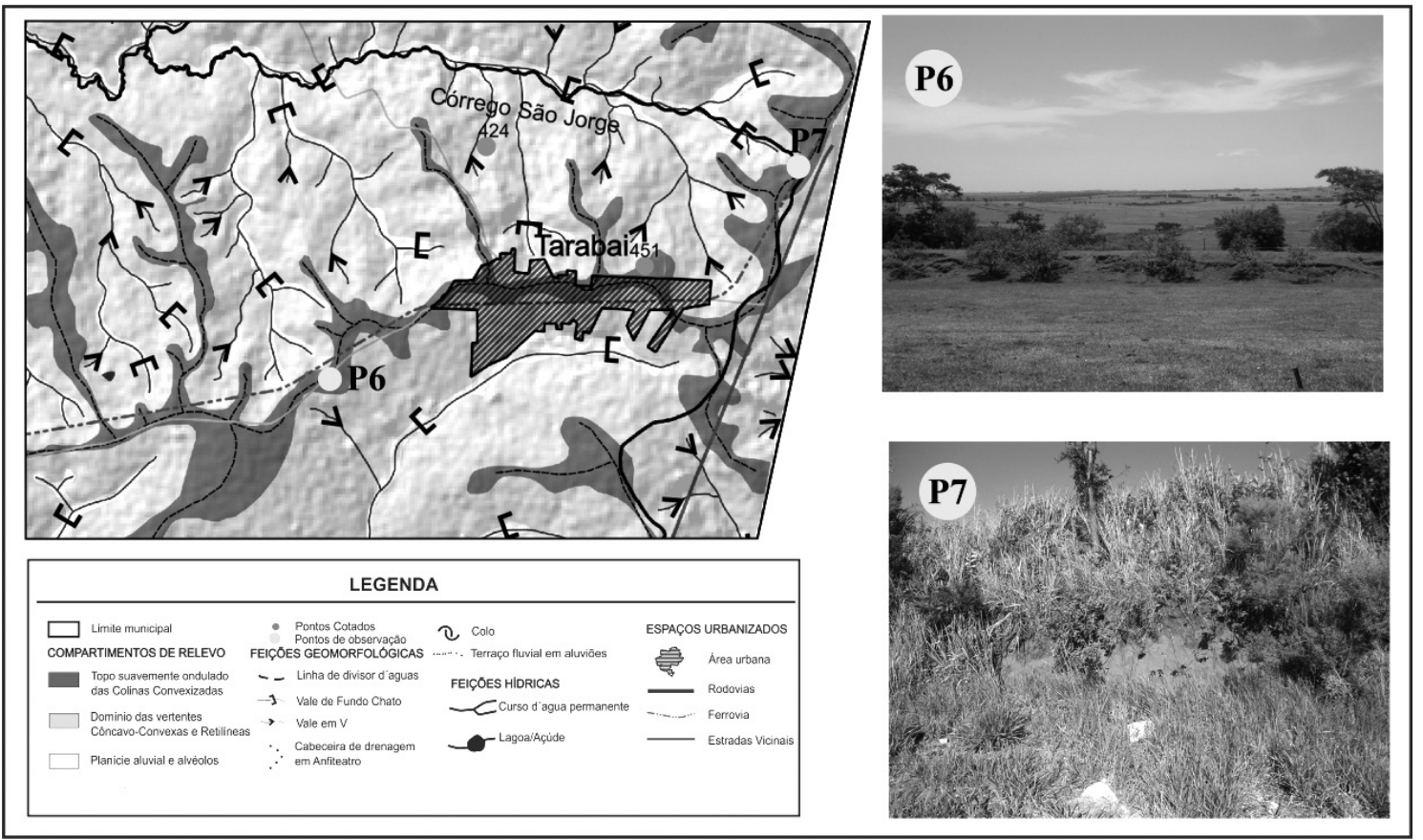

Figura 8

Pontos de observação com topos estreitos alongados.

Fonte: Felipe (2015)

\section{Considerações finais}

0 principal resultado desta pesquisa é a elaboração do Mapa dos compartimentos do relevo do município de Estrela do Norte-SP e adjacências. Desse modo, realizou-se uma análise dos compartimentos do relevo e da estrutura superficial da paisagem, buscando identificar a constituição litológica e pedológica das morfologias mapeadas e a dinâmica do uso e ocupação da terra.
$\mathrm{Na}$ área de estudo, próximo as cidades de Tarabai e Estrela do Norte o relevo apresenta topos estreitos e vertentes mais declivosas, presença de Argissolos e Neossolos, indicando a provável presença de maior concentração de carbonato de cálcio (agente cimentante). Em direção ao município de Mirante do Paranapanema e Sandovalina, há o predomínio dos topos amplos e suavemente ondulados com solos mais profundos (Latossolos), sendo frequente nessa paisagem o cultivo da cana de açúcar. 
Portanto, com os resultados desta pesquisa, espera-se que sirva como modelo de técnica cartográfica para a representação das formas de relevo, e que a metodologia utilizada possa ser aplicada em outras áreas e municípios, destacando o uso do sistema de processamento de imagens PushAnaglifo como nova tecnologia extremamente útil e prática, para a extração dos compartimentos de relevo e feições morfológicas.

Dessa forma, a etapa de identificação dos compartimentos de relevo e de algumas feições morfológicas foi atingida. Assim, o mapa poderá auxiliar nos estudos acadêmicos que vem sendo realizado na região do Pontal do Paranapanema com ênfase na recuperação de áreas degradadas ocasionadas por processos erosivos lineares e laminares, decorrentes da história de ocupação do uso da terra em área com susceptibilidade natural, entre outros projetos.

\section{Referências Bibliográficas}

Ab'Saber, A. N. (1969). Um conceito de geomorfologia a serviço das pesquisas sobre o quaternário. Geomorfologia, São Paulo, n 18, 1-23.

Amorim, A. (2000). Utilização de modelos estereoscópicos híbridos na atualização cartográfica. Tese Doutorado em Engenharia Civil - Escola de Engenharia de São Carlos, Universidade de São Paulo, São Carlos.

Barreto, M. J. \& Thomaz Junior, A. (2012). Os impactos territoriais da monocultura da cana-de-açúcar no Pontal do Paranapanema-SP. Revista Pegada, vol. 13, $\mathrm{n}^{\circ} 2,46-68$.

Barros, R. S. et al. (2008). Avaliação Planimétrica de Imagens ALOS/PRISM nível 1B2G. In II Simpósio Brasileiro de Ciências Geodésicas e Tecnologias da Geoinformação, Recife. Anais.. CDROM.

Cailleux, A. \& Tricart, J. (1956). Le problème de la classification des faits géomorphologiques. Ann. de Géogr..

Felipe, M. C. P. (2015). Mapeamento dos compartimentos de relevo do município de Estrela do Norte-SP e adjacências. $106 \mathrm{f}$. Trabalho de conclusão de curso (Graduação em Geografia) - Faculdade de Ciências e Tecnologia, Universidade Estadual Paulista, Presidente Prudente, 2015.

Instituto Brasileiro De Geografia E Estatística (IBGE). Censo Demográfico 2010. Rio de Janeiro: IBGE.

Instituto De Pesquisas Tecnológicas Do Estado De São Paulo (IPT) (1981a). Mapa geológico do Estado de São Paulo: 1:500.000. São Paulo: IPT, vol. I, (Publicação IPT 1184).

Instituto De Pesquisas Tecnológicas Do Estado De São Paulo (IPT) (1981b). Mapa geomorfológico do Estado de São
Paulo: 1:1.000.000. São Paulo: IPT, vol. II, (Publicação IPT 1183).

Moroz-Caccia Gouveia, I. C. et al. Contribuição ao planejamento de recursos hídricos em bacia hidrográfica: Geomorfologia e fragilidade Geoambiental da UGRH Paranapanema. Revista do Departamento de Geografia, vol. 27, 21-46, 2014.

Nunes, J. O. R. et al. (2014). Elaboração do Mapa dos Compartimentos de Relevo de parte do Município de Santo Anastácio-SP através das imagens tridimensionais ALOS PRISM. In: X Simpósio Nacional de Geomorfologia, Manaus. Anais... Manaus.

Nunes, J. O. R. et al. (2006). Mapa geomorfológico do perímetro urbano da cidade de Presidente Prudente. In VI Simpósio Nacional de Geomorfologia e Regional Conference on Geomorphology, Goiânia. Anais...CDROM.

Nunes, J. O. R. \& Fushimi, M. (2010). Mapeamento geomorfológico do município de Presidente PrudenteSP. In VIII Simpósio Nacional de Geomorfologia, III Encontro Latino Americano de Geomorfologia, I Encontro Ibero-Americano de Geomorfologia e I Encontro Ibero-Americano do Quaternário. Recife. Anais... Recife: UFPE, 2010.

Ross, J. L. S. \& Moroz, I. C. (1997). Mapa Geomorfológico do Estado de São Paulo. São Paulo: Revista do Departamento de Geografia, $\mathrm{n}^{\circ} 10$.

Ross, J. L. S. (1992). O registro cartográfico dos fatos geomórficos e a questão da taxonomia do relevo. São Paulo: Revista do Departamento de Geografia, $\mathrm{n}^{\circ} 6$, 17-29.

Santos, C. A. M. (2006). Formas de relevo da cidade de Marília-SP. 52 p. Trabalho de conclusão de curso (Graduação em Geografia) - Faculdade de Ciências e Tecnologia, Universidade Estadual Paulista, Presidente Prudente.

Suertegaray, D. M. A. \& Nunes, J. O. R. (2001). A natureza da Geografia Física. Rev. Terra Livre, São Paulo, $n^{\circ}$ 17, 11-27.

Tricart, J. (1965). Principes et méthodes de la géomophologie. Paris: Masson e Cie.

Vinha, T. M. (2011). Elementos para elaboração de SIG no planejamento e gestão para expansão urbana em Álvares Machado-SP. Não paginado. Dissertação de Mestrado em Geografia - Faculdade de Ciências e Tecnologia, Universidade Estadual Paulista, Presidente Prudente.

Texto recebido em/Text submitted on: 31/03/2016 Texto aprovado em/Text approved on: 03/10/2016 